(C) 2018, THE AUTHORS. Published by FASS Inc. and Elsevier Inc. on behalf of the American Dairy Science Association ${ }^{\circledR}$. This is an open access article under the CC BY 2.0 license (http://creativecommons.org/licenses/by/2.0/).

\title{
Effect of ammonia fiber expansion on the available energy content of wheat straw fed to lactating cattle and buffalo in India
}

\author{
Preeti Mor, ${ }^{*}$ Bryan Bals, $†$ Amrish Kumar Tyagi, ${ }^{*}$ Farzaneh Teymouri, $†$ Nitin Tyagi, ${ }^{*}$ Sachin Kumar, \\ Venkataraman Bringi, $\neq$ and Michael VandeHaar ${ }^{1}$ \\ ${ }^{*}$ Dairy Cattle Nutrition Division, National Dairy Research Institute, Karnal, Haryana 132001, India \\ †Michigan Biotechnology Institute, 3815 Technology Blvd, Lansing 48910 \\ ‡Department of Chemical Engineering and Material Science, Michigan State University, 428 S. Shaw Lane, East Lansing 48823 \\ $\S$ Department of Animal Science, Michigan State University, 2265 Anthony Hall, East Lansing 48823
}

\section{ABSTRACT}

The seasonal lack of availability of lush green forages can force dairy farmers in developing nations to rely on crop residues such as wheat and rice straw as the major feed source. We tested whether ammonia fiber expansion (AFEX) treatment of wheat straw would increase the energy available to Murrah buffalo and Karan-Fries cattle consuming $70 \%$ of their diet as wheat straw in India. Forty lactating animals of each species were blocked by parity and days in milk and randomly assigned to 1 of 4 treatment diets $(\mathrm{n}=10)$. Treatments were a nutrient-rich diet with 0 to $20 \%$ straw (positive control; PC) and 3 high-straw diets with various levels of AFEX-treatment: (1) $70 \%$ untreated straw (no AFEX), (2) 40 to $45 \%$ untreated straw with 25 to 30\% AFEX-treated straw (low AFEX), and (3) 20\% untreated straw with 50\% AFEX-treated straw (high AFEX). The AFEX-treated straw was pelleted. Urea was added to the no and low AFEX diets so they were isonitrogenous with the high AFEX diet. Animals were individually fed the PC diet for $14 \mathrm{~d}$ followed by $7 \mathrm{~d}$ of adaptation to treatments, full treatments for 28 to 35 $\mathrm{d}$, and finally PC diets for $21 \mathrm{~d}$. Compared with buffalo fed the PC diet, those fed high-straw diets consumed $29 \%$ less feed dry matter, put out $16 \%$ less milk energy, and lost $0.8 \mathrm{~kg} / \mathrm{d}$ more body weight; the AFEX treatment of straw did not alter intake or milk production but greatly ameliorated the body weight loss $(-1.0$ $\mathrm{kg} / \mathrm{d}$ for no AFEX and $-0.07 \mathrm{~kg} / \mathrm{d}$ for high AFEX). In Karan-Fries cattle, high-straw diets decreased dry matter intake by $39 \%$ and milk energy by $24 \%$, and the high AFEX diet increased intake by $42 \%$ and milk energy by $18 \%$. The AFEX treatment increased digestibilities of organic matter, dry matter, neutral detergent fiber, acid detergent fiber, and crude protein by

Received February 12, 2018.

Accepted May 13, 2018.

${ }^{1}$ Corresponding author: mikevh@msu.edu
6 to 13 percentage points in buffalo and 5 to 10 points in cattle. In conclusion, AFEX treatment increased the digestibility and energy availability of wheat straw for lactating buffalo and cattle and has commercial potential to improve milk production and feed efficiency when high-quality forages or grains are not available.

Key words: ammonia fiber expansion, Murrah buffalo, dairy cow, energy intake

\section{INTRODUCTION}

India is the world's largest milk producer and is expected to see increased demand for dairy products in the near future (Deshmukh and Jadhav, 2015). This demand is placing substantial stress on the supply of feed for cattle and buffalo, particularly as per-animal productivity in India remains low relative to that of animals in the industrialized world. Of particular concern is the availability and seasonality of lush green forages, as ensiling is not a common practice in many parts of the country nor is it practical for small farmers. The Indian government predicted a $33 \%$ shortage of green forage from 2012 to 2017, and such shortages are expected to continue (Government of India, 2011). In contrast, rice and wheat straw residues are abundant in several parts of India, particularly in the northwest states of Punjab and Haryana. Although wheat straw is currently used throughout India as a cattle feed ingredient (Mishra et al., 2010), rice straw in particular is often left on the field and burned, causing severe pollution and health problems in Delhi and surrounding regions (Sharma et al., 2010; Yadav et al., 2014). Because of this pollution, the Indian government is encouraging alternative uses of straw.

One approach to improve feed quality and reduce pollution from burning straw is to treat or supplement the straw to improve its nutritional quality. Urea-molasses blocks, for example, have been studied as an approach for improving productivity in Latin America, Africa, and Asia (FAO, 2007). Likewise, alkaline treatment 
of straw, particularly with lime or ammonia, has been shown to improve the digestibility of the fiber (Schiere and de Wit, 1995; Sarnklong et al., 2010). Although often effective, these alkaline treatments have struggled to obtain commercial acceptance due in part to the high labor requirements for the local farmers and the difficulties of handling toxic chemicals such as ammonia on-farm.

An alternative alkaline treatment is ammonia fiber expansion (AFEX), which involves exposing the straw to high levels of ammonia at elevated temperature and pressure for $<1 \mathrm{~h}$. Unlike traditional approaches to treat straw, AFEX treatment would be performed at a local industrial center, and the finished product can be pelleted to facilitate long-distance transportation of the feed (Eranki et al., 2011). Thus, AFEX pellets can be supplied to areas with seasonal scarcity of forages without significantly burdening a farmer's time or available resources. Furthermore, in vitro tests have demonstrated that AFEX increases the digestibility of fodder to a greater extent than other on-farm treatments (Bals et al., 2010; Scott et al., 2011). Initial in vitro digestibility of NDF was increased 19 to 20 percentage points for corn stover and wheat straw (Bals et al., 2010). Likewise, AFEX treatment of barley straw increased in vitro production of VFA from 51 to $60 \mathrm{mmol} / \mathrm{d}$, compared with untreated barley straw (Griffith et al., 2016). Feeding trials with AFEX-treated straw have been limited to date, although preliminary experiments have demonstrated that the material is palatable and maintains the general health of the animals (Weimer et al., 2003; Blummel et al., 2014).

Thus, the overall goal in this project was to determine the effectiveness of AFEX treatment on wheat straw as a feed ingredient for Indian dairy cattle and buffalo. We hypothesized that AFEX treatment would increase the digestibility and apparent $\mathrm{NE}_{\mathrm{L}}$ value of wheat straw and increase milk production over ureasupplemented wheat straw. If our hypothesis was correct, then AFEX treatment could be used to provide a reasonable replacement for fresh green forages during the dry season. We devised 2 experiments to test these hypotheses in cattle and buffalo, with both experiments using breeds commonly found in India. In addition, a sensory evaluation of the milk was performed to determine whether AFEX treatment had any negative effect on milk flavor.

\section{MATERIALS AND METHODS}

\section{Animals}

Experimental procedures were approved by the Institutional Animal Ethics Committee and Institute Animal
Allotment Committee at the National Dairy Research Institute (NDRI) in Karnal, Haryana, India. Studies were performed at NDRI's research farm between October 2016 and January 2017. As a precautionary measure, milk from animals consuming AFEX pellets was not allowed to enter the human food chain other than for the sensory evaluation, which was conducted with the approval of the Michigan State University Institutional Review Board, Human Research Protection Programs.

Forty Murrah buffalo and 40 Karan-Fries cattle were used for these experiments. No animals were pregnant during the course of the study. Animals were blocked by parity (first, second, or third or later lactation) and stage of lactation and randomly assigned within block to 1 of 4 treatments. Buffaloes had an average of 72 DIM (SD 42) and cows had an average of 96 DIM (SD 34 ) at the start of the trial. Animals were housed in individual tiestalls in a barn, with all animals from each experiment on the same side of the barn. The barn was oriented in a north-south direction, and thus all animals received roughly equal sunlight. Before the experiment, all animals were given ivermectin (100 mg) and fenbendazole $(3 \mathrm{~g})$ for deworming (Fendikind-Plus, Mankind Pharma Ltd., New Delhi, India). Animals were milked by hand twice a day at approximately 0600 and $1800 \mathrm{~h}$. Animals were provided with $2 \mathrm{~h}$ of exercise in an open area (at approximately 0800 to 1000 h) before being offered the forage for the day. Animals had access to water 3 times per day (after each milking and at approximately $1400 \mathrm{~h}$ ) by providing a bucket with water and allowing each animal to drink as long as desired.

\section{Diets}

Treatments were a nutrient-rich diet with 0 to $20 \%$ straw (positive control; PC) and 3 high-straw diets with 3 levels of AFEX treatment: (1) $70 \%$ untreated straw (no AFEX), (2) 40 to $45 \%$ untreated straw with 25 to 30\% AFEX-treated straw (low AFEX), and (3) $20 \%$ untreated straw with $50 \%$ AFEX-treated straw (high AFEX). The AFEX-treated straw was pelleted and the untreated wheat straw was chopped to a particle size of $\sim 4 \mathrm{~cm}$. Urea was added to straw in the no and low AFEX diets to keep these diets isonitrogenous with the high AFEX diet; no attempt was made to make the PC diet isonitrogenous with the high-straw diets, as it was designed to show the animals' potential under optimum nutrition. Diets as consumed are shown in Tables 1 and 2 for buffalo and cattle, respectively, and the composition of the feed ingredients is shown in Table 3. Moisture content of feeds was tested weekly, and composition was tested every other week. For buf- 
Table 1. Composition and formulation of each diet (\% of DMI) in the Murrah buffalo experiment ${ }^{1}$

\begin{tabular}{|c|c|c|c|c|}
\hline \multirow[b]{2}{*}{ Composition } & \multicolumn{3}{|c|}{ High-straw diet } & \multirow{2}{*}{$\begin{array}{l}\text { Positive } \\
\text { control }\end{array}$} \\
\hline & No AFEX & Low AFEX & High AFEX & \\
\hline Corn grain & $3.1 \pm 0.1$ & $2.9 \pm 0.0$ & $2.9 \pm 0.0$ & $11.8 \pm 0.1$ \\
\hline Mustard oilcake & $2.0 \pm 0.1$ & $2.0 \pm 0.0$ & $1.9 \pm 0.0$ & $7.9 \pm 0.0$ \\
\hline Soybean meal & $1.7 \pm 0.0$ & $1.7 \pm 0.0$ & $1.6 \pm 0.0$ & $6.7 \pm 0.0$ \\
\hline Wheat bran & $1.7 \pm 0.0$ & $1.7 \pm 0.0$ & $1.6 \pm 0.0$ & $6.7 \pm 0.0$ \\
\hline Peanut cake & $1.3 \pm 0.0$ & $1.3 \pm 0.0$ & $1.2 \pm 0.0$ & $5.1 \pm 0.0$ \\
\hline Sorghum forage & $20.5 \pm 0.6$ & $19.6 \pm 0.2$ & $19.1 \pm 0.2$ & $39.3 \pm 0.2$ \\
\hline Wheat straw & $68.6 \pm 0.9$ & $44.8 \pm 0.6$ & $22.8 \pm 0.5$ & $21.4 \pm 0.4$ \\
\hline AFEX pellets & - & $25.3 \pm 0.2$ & $48.5 \pm 0.6$ & - \\
\hline Urea & $0.7 \pm 0.0$ & $0.4 \pm 0.0$ & - & - \\
\hline Minerals $^{2}$ & $0.3 \pm 0.0$ & $0.3 \pm 0.0$ & $0.3 \pm 0.0$ & $1.2 \pm 0.0$ \\
\hline $\mathrm{NDF}$ & $64.5 \pm 1.0$ & $64.5 \pm 0.7$ & $64.6 \pm 0.9$ & $46.7 \pm 0.5$ \\
\hline $\mathrm{ADF}$ & $44.3 \pm 0.7$ & $46.3 \pm 0.5$ & $48.1 \pm 0.7$ & $28.1 \pm 0.3$ \\
\hline $\mathrm{CP}$ & $10.4 \pm 0.2$ & $11.3 \pm 0.1$ & $11.5 \pm 0.2$ & $15.5 \pm 0.1$ \\
\hline Starch & $3.0 \pm 0.1$ & $2.9 \pm 0.0$ & $2.7 \pm 0.0$ & $8.6 \pm 0.1$ \\
\hline Ash & $11.1 \pm 0.2$ & $9.6 \pm 0.1$ & $8.2 \pm 0.1$ & $10.0 \pm 0.1$ \\
\hline
\end{tabular}

${ }^{1}$ All values are the average amount consumed over the course of the treatment period \pm SEM. No AFEX (ammonia fiber expansion) $=70 \%$ untreated straw; low AFEX $=45 \%$ untreated straw with $25 \%$ AFEX-treated straw; high AFEX $=20 \%$ untreated straw with 50\% AFEX-treated straw; positive control = nutrient-rich diet with $20 \%$ straw.

${ }^{2}$ Mineral mix is $31 \%$ salt, $31 \%$ calcite, $19 \%$ dicalcium phosphate, $9 \%$ soda bicarbonate, $3 \%$ magnesium oxide, and $7 \%$ trace minerals (KemTrace Maxim, Kemin Industries, Chennai, India).

falo (experiment 1), PC was intended to demonstrate the maximum potential of the animals, and the no AFEX diet was designed as a negative control diet that animals might actually be fed during the dry season. The no AFEX buffalo diet contained $69 \%$ wheat straw (mixed with 1\% urea, wt/wt), $20 \%$ fresh sorghum forage, and $10 \%$ concentrate. The low concentrate value in particular is common for buffalo from low-income farmers, and farmers are unlikely to adjust the balance of any mineral supplementation (Amrish Tyagi, NDRI, Karnal, India; personal communication). For cattle (experiment 2), the PC diet was intended to replicate a commercial diet fed during the rainy season when fresh green forage is readily available, and the no AFEX diet was a negative control diet that animals might be fed during the dry season. All cattle diets contained $30 \%$

Table 2. Composition and formulation of each diet (\% of DMI) in the Karan-Fries cattle experiment ${ }^{1}$

\begin{tabular}{|c|c|c|c|c|}
\hline \multirow[b]{2}{*}{ Composition } & \multicolumn{3}{|c|}{ High-straw diet } & \multirow{2}{*}{$\begin{array}{l}\text { Positive } \\
\text { control }\end{array}$} \\
\hline & No AFEX & Low AFEX & High AFEX & \\
\hline Corn grain & $10.2 \pm 0.4$ & $8.7 \pm 0.1$ & $8.4 \pm 0.1$ & $9.0 \pm 0.1$ \\
\hline Mustard oilcake & $6.8 \pm 0.3$ & $5.8 \pm 0.1$ & $5.6 \pm 0.1$ & $6.0 \pm 0.0$ \\
\hline Soybean meal & $5.8 \pm 0.2$ & $4.9 \pm 0.1$ & $4.8 \pm 0.1$ & $5.1 \pm 0.0$ \\
\hline Wheat bran & $5.8 \pm 0.2$ & $4.9 \pm 0.1$ & $4.8 \pm 0.1$ & $5.1 \pm 0.0$ \\
\hline Peanut cake & $4.4 \pm 0.2$ & $3.8 \pm 0.1$ & $3.6 \pm 0.0$ & $3.9 \pm 0.0$ \\
\hline Sorghum forage & - & - & - & $70.0 \pm 0.2$ \\
\hline Wheat straw & $65.5 \pm 1.3$ & $39.2 \pm 0.8$ & $22.6 \pm 0.7$ & - \\
\hline AFEX pellets & - & $31.5 \pm 0.4$ & $49.4 \pm 0.4$ & - \\
\hline Urea & $0.7 \pm 0.0$ & $0.4 \pm 0.0$ & - & - \\
\hline Minerals $^{2}$ & $1.0 \pm 0.0$ & $0.9 \pm 0.0$ & $0.8 \pm 0.0$ & $0.9 \pm 0.0$ \\
\hline NDF & $53.3 \pm 1.2$ & $55.7 \pm 0.9$ & $56.1 \pm 0.9$ & $48.7 \pm 0.1$ \\
\hline $\mathrm{ADF}$ & $40.0 \pm 0.9$ & $44.0 \pm 0.7$ & $45.7 \pm 0.7$ & $24.0 \pm 0.1$ \\
\hline $\mathrm{CP}$ & $13.5 \pm 0.5$ & $14.0 \pm 0.3$ & $13.9 \pm 0.2$ & $15.7 \pm 0.1$ \\
\hline Starch & $6.9 \pm 0.3$ & $6.0 \pm 0.1$ & $5.7 \pm 0.1$ & $7.5 \pm 0.0$ \\
\hline Ash & $10.5 \pm 0.3$ & $8.7 \pm 0.1$ & $7.7 \pm 0.1$ & $10.0 \pm 0.0$ \\
\hline
\end{tabular}

${ }^{1}$ All values are the average amount consumed over the course of the treatment period \pm SEM. No AFEX (ammonia fiber expansion $)=70 \%$ untreated straw; low AFEX $=40 \%$ untreated straw with $30 \%$ AFEX-treated straw; high AFEX $=20 \%$ untreated straw with 50\% AFEX-treated straw; positive control = nutrient-rich diet with $20 \%$ straw.

${ }^{2}$ Mineral mix is $31 \%$ salt, $31 \%$ calcite, $19 \%$ dicalcium phosphate, $9 \%$ soda bicarbonate, $3 \%$ magnesium oxide, and $7 \%$ trace minerals (KemTrace Maxim, Kemin Industries, Chennai, India). 
concentrate; PC contained $70 \%$ fresh sorghum forage, and the high-straw diets contained $70 \%$ straw with 0 , 30 , or $50 \%$ of the straw being treated by AFEX.

The concentrate was a blend of 30\% corn grain, $20 \%$ mustard oilcake, $17 \%$ soybean meal, $17 \%$ wheat bran, $13 \%$ peanut cake, and 3\% minerals. Initially, the green forage was immature maize harvested at NDRI farms, but due to the diminishing quality of the maize, forage sorghum ('Sugar Graze' cultivar) was fed starting at the onset of the treatment phase of the experiments. Wheat straw fed during the pretreatment phase was harvested in India, whereas straw fed during the treatment phase was harvested in Leslie, Michigan, and shipped to NDRI as long straw. Urea was added by producing a $1 \%$ solution of urea and mixing equal parts (by weight) of straw and urea solution just before feeding. The AFEX treatment was performed in Lansing, Michigan, using a pair of 450-L packed bed reactors and pelleted at $6 \mathrm{~mm}$ diameter using a Buskirk Engineering (Ossian, IN) PM 810 pelletizer in the manner described in Sarks et al. (2016). An in vitro NDF digestibility experiment was performed on both treated and untreated straw according to Goering and Van Soest (1970) by Cumberland Valley Analytical Services (Waynesboro, PA).

For all diets, straw was provided ad libitum with the goal of feeding each animal $1.5 \mathrm{~kg}$ more wheat straw than it would consume, except for the cow PC diet, in which fresh sorghum forage was provided ad libitum. All other feeds were provided in the amounts required to maintain the correct proportion of the expected daily intake based on the amount consumed the previous day. For each animal, the previous day's DMI was used to recalculate the amount of feed to provide to the animals the following day. The concentrates and minerals were mixed before the start of the study; all other feeds were added separately rather than as a TMR to prevent spoilage of concentrate. Animals were fed 3 times per day: concentrate and AFEX-treated straw pellets were provided immediately before each milking (0600 and $1800 \mathrm{~h}$ ), whereas straw and sorghum forage were provided at approximately $1000 \mathrm{~h}$. Access to feed

Table 3. Composition ( $\mathrm{g} / \mathrm{kg}$ of DM) of concentrate, forage sorghum, untreated wheat straw, and ammonia fiber expansion (AFEX)-treated wheat straw used in this study

\begin{tabular}{lccrr}
\hline Item & NDF & ADF & CP & Ash \\
\hline Concentrate $^{1}$ & 165 & 138 & 247 & 82 \\
Sorghum forage & 625 & 284 & 119 & 108 \\
Wheat straw & 729 & 540 & 51 & 118 \\
AFEX pellets & 709 & 599 & 118 & 55 \\
\hline
\end{tabular}

${ }^{1}$ Concentrate was a blend of corn grain, mustard oilcake, soybean meal, wheat bran, peanut cake, and minerals in the ratio shown in Tables 1 and 2. was blocked from 0800 to $1000 \mathrm{~h}$ to allow orts to be collected and measured. All animals had either straw or sorghum forage available at all other times of the day. Moisture contents of orts were measured twice a week by drying at $100^{\circ} \mathrm{C}$, and formulation of the diets adjusted as necessary. Visual inspection of orts confirmed that consumption of AFEX pellets and concentrate (as well as consumption of green fodder for buffalo) was virtually complete on each day. Thus, in calculating the percentages of feed consumed, we assumed that all orts were wheat straw, with the exception of green fodder for cattle on the PC diet.

Both experiments were designed with a pretreatment phase, lasting $2 \mathrm{wk}$, during which all animals were fed the PC diet. This was followed by a week in which the animals were transitioned to their treatment diets by substituting in one-eighth of the new diet each day. In other words, the diet on $\mathrm{d} 1$ of the transition week was seven-eighths PC diet and one-eighth treatment diet, d 2 was six-eighths PC diet and two-eighths treatment diet, and so on, such that the diet was all treatment diet on $\mathrm{d} 1$ of the treatment period. The treatment period lasted $4 \mathrm{wk}$ for cattle and $5 \mathrm{wk}$ for buffalo. Finally, all animals were fed PC for a 3 -wk post-treatment period.

\section{Measurements}

Total DMI and milk production were measured daily using a KBC (Karnal, India) digital weighing scale accurate to $0.005 \mathrm{~kg}$. Milk composition (fat, SNF, true protein, lactose) for both the morning and evening milk was measured on 3 consecutive days per week using a Lactoscan S Milk Analyzer (Nova Zagoria, Bulgaria). Milk energy was then calculated from the weekly average of milk yield and composition using the following equation (NRC, 2001):

$$
\begin{gathered}
\text { Milk energy }(\mathrm{Mcal} / \mathrm{d})=[9.29 \times \text { fat }(\mathrm{kg}) \\
+5.63 \times \text { protein }(\mathrm{kg})+3.95 \times \text { lactose }(\mathrm{kg})] .
\end{gathered}
$$

The DM of feeds was measured by the difference in weight before and after drying feed samples in a $100^{\circ} \mathrm{C}$ free-convection oven overnight. Van Soest et al. (1991) recommend that DM be determined in a forced convection oven at lower temperature to prevent artifacts in composition analysis, but such an oven was unavailable at the time. Body weights were measured after morning milking and before the $1000 \mathrm{~h}$ feeding on 2 consecutive days each week. Body condition scores (1-5 scale) were assessed every 2 wk by 3 trained experts, remaining blind to each other and to treatment. Apparent net energy (NE) intake was defined as the sum of NE for 
gain (or loss), $\mathrm{NE}_{\mathrm{M}}$, and milk energy. The $\mathrm{NE}_{\mathrm{G}}$ was calculated as $7 \mathrm{Mcal} / \mathrm{kg}$ of $\mathrm{BW}$ change. The $\mathrm{NE}_{\mathrm{M}}$ was calculated as 0.08 multiplied by $\mathrm{BW}^{0.75}$ (metabolic BW). Feed gross energetic efficiency was defined as the sum of $\mathrm{NE}_{\mathrm{G}}$ and milk energy divided by total feed gross energy based on the DMI of each animal. Gross feed energy was assumed to be $4.5 \mathrm{Mcal} / \mathrm{kg}$ of DM (AFRC, 1993). Apparent $\mathrm{NE}_{\mathrm{L}}$ density was defined as apparent NE intake divided by DM intake.

\section{Digestibility Study}

During wk 3 of the treatment period, 6 animals from each treatment were used to measure total digestibility of solids, fiber, and nitrogen. For 1 wk, these animals were kept in stalls and all fecal matter was collected. Total fecal mass for each day for each animal was measured and mixed, and a sample was dried at $100^{\circ} \mathrm{C}$ overnight to measure DM content and to keep for pooling. Dried fecal samples from each animal for all $7 \mathrm{~d}$ were pooled based on amount excreted each day, mixed, and measured for OM, NDF (with amylase addition), and ADF using standard methods (Van Soest et al., 1991). Undried samples were stored with $25 \mathrm{~mL}$ of $25 \%$ sulfuric acid added per day as a preservative, pooled together over $7 \mathrm{~d}$ based on the amount excreted, and measured for $\mathrm{CP}$ content. Orts were also collected each day, pooled for each animal, and OM, CP, NDF, and $\mathrm{ADF}$ were measured. Intake of each component was calculated as the difference between the amount offered of each component and amount in the orts. Digestibility was calculated as the difference between intake of each component and the amount in feces divided by the intake.

\section{Sensory Analysis}

To determine whether compounds produced during the AFEX process, or metabolites of these compounds, were secreted into milk and could produce a detectable flavor, a sensory analysis was performed using unpasteurized milk obtained from the last week of treatment. Milk was pooled from all animals in each treatment using a weighted average of each animal's milk yield. The pooled samples were divided into 6 portions and given a randomly assigned code. Three sensory analysis experts at NDRI were assigned to determine whether an improper aroma was detected and, if not, to taste the milk and rate it for unusual flavors. Each expert received duplicates of milk from each treatment group, and the particular treatment was blind to both the expert and the administrator of the test. No statistical analysis was performed on the data obtained from the sensory analysis.

\section{Statistical Analysis}

All statistical analyses were performed using SAS 9.4 software (SAS Institute Inc., Cary, NC). A weekly average of every response variable to be analyzed was obtained for each animal. Each response variable was then analyzed using PROC GLIMMIX by week, using the pretreatment period response as a covariate. Fixed effects were the pretreatment covariate, a fourth-order polynomial on DIM, parity, week, treatment, and treatment $\times$ week interactions, and animals within treatments as a random effect. Response variables during the treatment period were compared using orthogonal contrasts of (1) PC versus all other treatments (all high-straw diets), (2) linear effect of AFEX (no AFEX, low AFEX, high AFEX), and (3) quadratic effect of AFEX. Coefficients were determined for the unevenly spaced treatments by generating orthogonal polynomials using the average AFEX intake for the 3 treatment groups (SAS 9.4), and these contrasts are shown in Table 4. In addition, pairwise comparisons were made on the treatment $x$ week interactions when the effect was significant for the post-treatment period as well as when considering specific weeks (Figures 1 and 2). Differences were considered significant at $P<0.05$ and tendencies at $P<0.10$.

\section{RESULTS}

\section{Experiment 1}

The greatest treatment effect of AFEX for the buffalo experiment was on BW, with no effect on milk production (Table 5). High-straw diets decreased milk production $(P=0.02)$ and milk energy output $(P<$ 0.01) of Murrah buffalo compared with the PC diet, but treatment of straw with AFEX had no effect on either. High straw also decreased the fat content in milk compared with PC $(P=0.02)$, and AFEX treatment of the straw partially restored fat content $(P<0.01$ for linear effect of AFEX). Buffalo fed PC gained $0.4 \mathrm{~kg}$ of

Table 4. Coefficients used for determining linear and quadratic contrasts in buffalo and cattle experiments

\begin{tabular}{lrrrrr}
\hline & \multicolumn{2}{c}{ Murrah buffalo } & & \multicolumn{2}{c}{ Karan-Fries cattle } \\
\cline { 2 - 3 } \cline { 6 - 6 } Item $^{1}$ & Linear & Quadratic & & Linear & Quadratic \\
\hline No AFEX & -0.717 & 0.390 & & -0.762 & 0.292 \\
Low AFEX & 0.020 & -0.816 & & 0.128 & -0.806 \\
High AFEX & 0.697 & 0.426 & & 0.634 & 0.514 \\
\hline
\end{tabular}

${ }^{1}$ No AFEX (ammonia fiber expansion) $=70 \%$ untreated straw; low AFEX $=40$ to $45 \%$ untreated straw with 25 to $30 \%$ AFEX-treated straw; high AFEX $=20 \%$ untreated straw with 50\% AFEX-treated straw. 


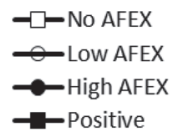

(a)

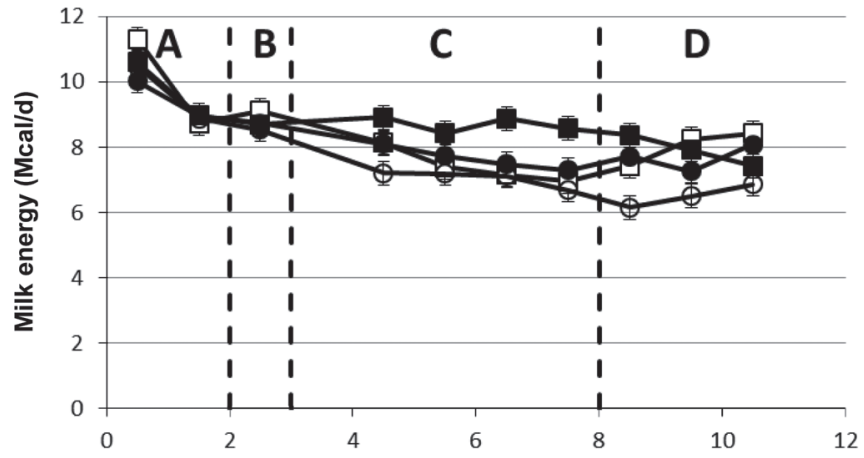

(b)

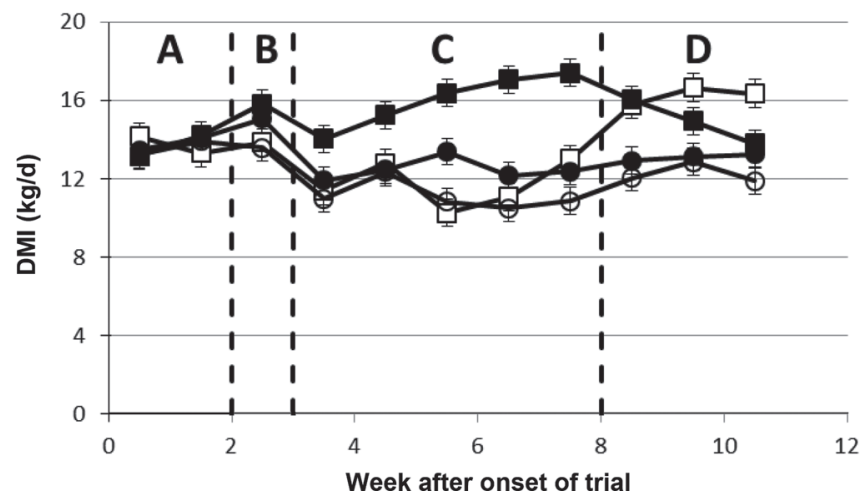

(c)

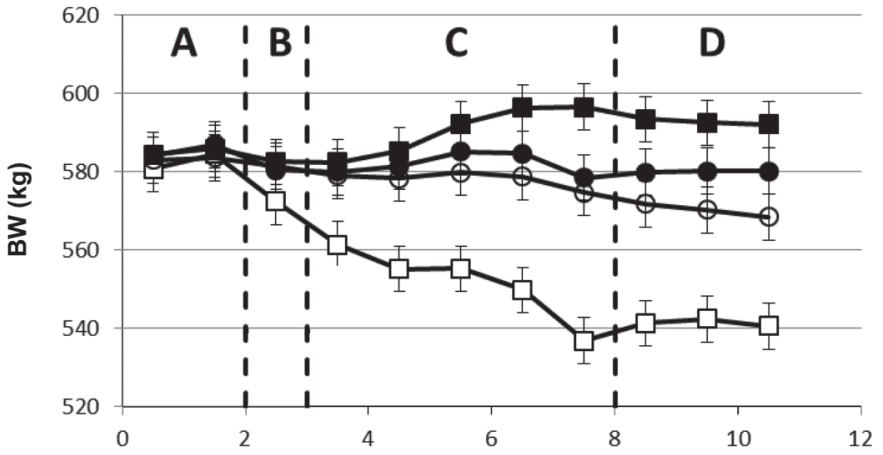

(d)

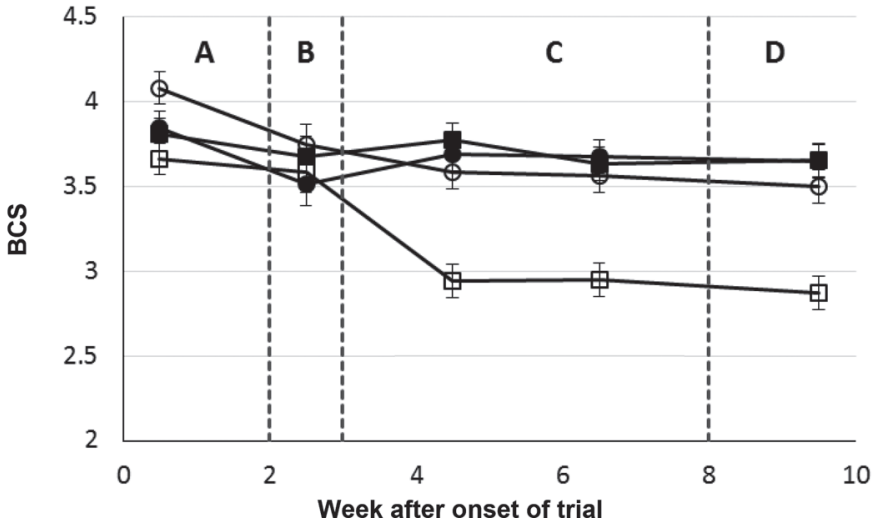

Figure 1. (a) Milk energy, (b) DMI, (c) BW, and (d) BCS over the course of experiment 1 with Murrah buffalo. Data are provided for (A) the pretreatment period, (B) the transition week to treatment diets, (C) the treatment period, and (D) the post-treatment period. No AFEX (ammonia fiber expansion) $=70 \%$ untreated straw; low AFEX $=45 \%$ untreated straw with $25 \%$ AFEX-treated straw; high AFEX $=20 \%$ untreated straw with 50\% AFEX-treated straw; positive = positive control nutrient-rich diet with $20 \%$ straw. All data shown are least squares means of the weekly averages of all buffalo in each treatment after covariate adjustment. Error bars represent the standard error of the treatment $\times$ week interaction. All animals were fed the positive control diet during the pre- and post-treatment periods.

$\mathrm{BW} / \mathrm{d}$ over the course of treatment, but those fed high straw lost $\mathrm{BW}(P<0.01$ for the difference). Animals fed the no AFEX diet lost $1.0 \mathrm{~kg} / \mathrm{d}$, and treatment of straw with AFEX reduced the loss to only $0.1 \mathrm{~kg} / \mathrm{d}$ $(P<0.01$ for linear effect of AFEX). These changes in $\mathrm{BW}$ led to changes in feed efficiency, apparent $\mathrm{NE}_{\mathrm{L}}$ intake, and apparent $\mathrm{NE}_{\mathrm{L}}$ density of the diets. Animals fed PC had greater BW $(P=0.01)$, greater apparent $\mathrm{NE}_{\mathrm{L}}$ intake $(P=0.01)$, and greater feed efficiency $(P<$ $0.01)$ than those fed high-straw diets. Increasing inclusion of AFEX-treated straw increased BW $(P<0.01)$, apparent $\mathrm{NE}_{\mathrm{L}}$ intake $(P=0.01)$, feed efficiency $(P<$ $0.01)$, and apparent $\mathrm{NE}_{\mathrm{L}}$ density $(P=0.02)$ in a linear fashion with no evidence for a quadratic effect. Dry matter intake was greater for animals fed PC than for those fed high-straw diets $(P<0.01)$.
Changes in BW, milk energy, DMI, and BCS for buffalo over the course of the study are shown in Figure 1. Buffalo fed the no AFEX diet lost BW once treatment commenced, with statistically significant $(P<0.01)$ losses in wk 4, 5, and 7. Although buffalo on the no AFEX diet lost no more weight once they were fed the PC diet, they did not gain weight during any week $(P$ $>0.05)$ of the post-treatment period, such that $\mathrm{BW}$ remained significantly different from that on $\mathrm{PC}$ diet $(P<0.01)$. This lack of increase in BW occurred despite the fact that the DMI of buffalo fed the no AFEX diet began to increase in the last 2 wk of the treatment period, and by the last $2 \mathrm{wk}$ of the post-treatment period, these buffalo had DMI equivalent to that of the $\mathrm{PC}$ group and statistically greater $(P<0.05)$ than that of the low and high AFEX groups. This greater intake 
was associated with an increase in milk energy output rather than $\mathrm{BW}$ repletion.

\section{Experiment 2}

In contrast to effects in buffalo, increasing inclusion of AFEX-treated straw increased DMI and milk production of Karan-Fries cattle (Table 6). Cattle fed highstraw diets had less milk yield and milk energy output than those fed the PC $\operatorname{diet}(P<0.01)$. Treatment with AFEX linearly increased milk yield $(P<0.01)$ and milk energy output $(P=0.02)$, with a tendency for a quadratic effect, indicating that the low AFEX diet was not very different from the no AFEX diet. The AFEX treatments did not greatly alter milk composition, although increasing AFEX caused a linear decrease in fat content $(P=0.05)$. Cattle fed high-straw diets consumed less feed than those fed PC $(P<0.01)$, with cattle fed the no AFEX diet eating only half as much as those fed the PC diet. Increasing inclusion of AFEXtreated straw increased DM intake $(P<0.01)$ as well as BW $(P=0.01)$. However, this change in BW occurred near the beginning of the experiment (Figure 2), and the magnitude of change among the high-straw diets was less than that observed in the buffalo experiment. Cattle fed PC had greater apparent $\mathrm{NE}_{\mathrm{L}}$ intake $(P<$ 0.01) than those fed high straw. Apparent $\mathrm{NE}_{\mathrm{L}}$ intake was not different among the high-straw diets, although we observed a weak tendency for increased $\mathrm{NE}_{\mathrm{L}}$ intake with increasing AFEX treatment $(P=0.13)$; AFEX did not affect the energetic efficiency of feed use $(P=$ 0.59). Apparent $\mathrm{NE}_{\mathrm{L}}$ density was not different for the 4 diets, and, if anything, was greatest for the untreated straw diet (no AFEX), likely because BW change was

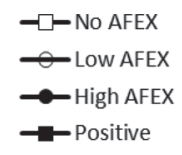

(a)

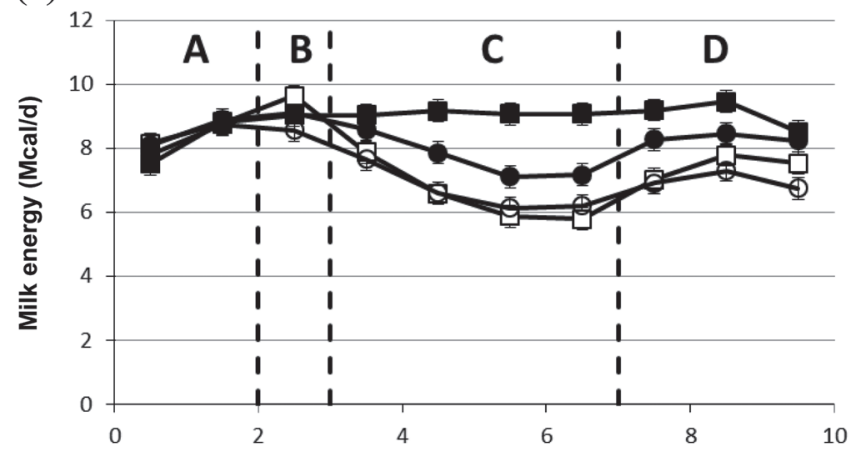

(b)

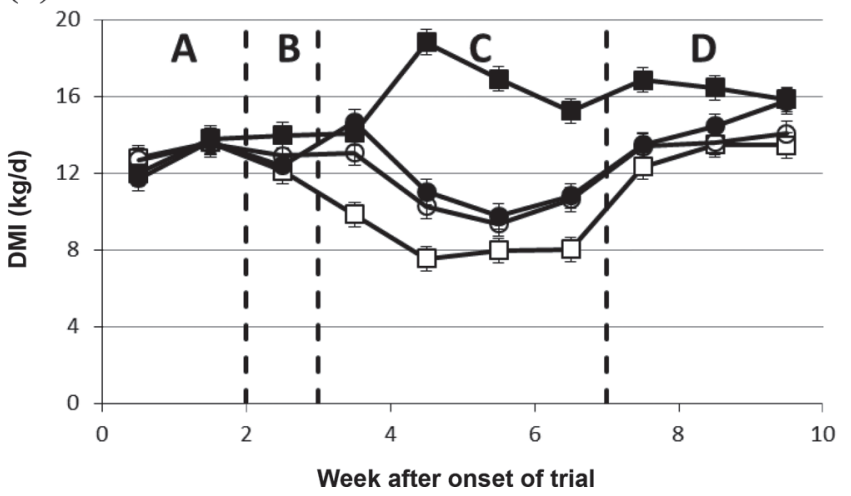

(c)

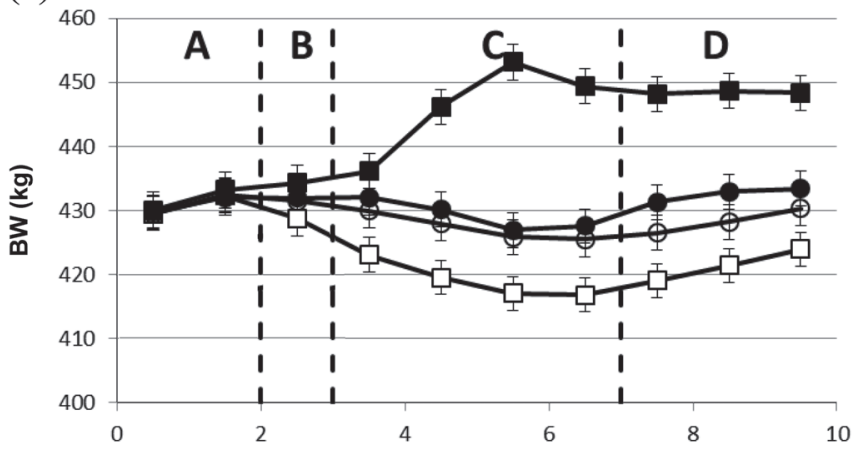

(d)

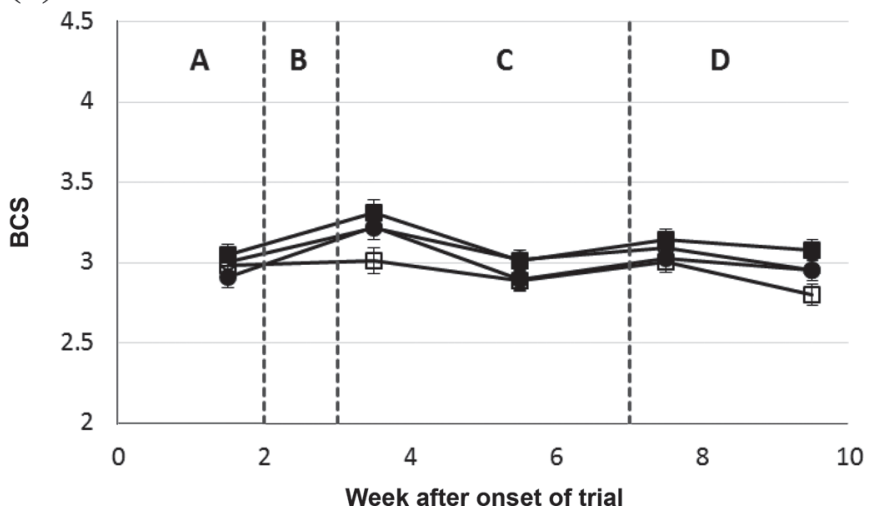

Figure 2. (a) Milk energy, (b) DMI, (c) BW, and (d) BCS over the course of experiment 2 with Karan-Fries cattle. Data are provided for (A) the pretreatment period, (B) the transition week to treatment diets, (C) the treatment period, and (D) the post-treatment period. No AFEX (ammonia fiber expansion) $=70 \%$ untreated straw; low AFEX $=40 \%$ untreated straw with 30\% AFEX-treated straw; high AFEX $=20 \%$ untreated straw with $50 \%$ AFEX-treated straw; positive = positive control nutrient-rich diet with $0 \%$ straw. All data shown are least squares means of the weekly averages of all cattle in each treatment after covariate adjustment. Error bars represent the standard error of the treatment $\times$ week interaction. All animals were fed the positive control diet during the pre- and post-treatment periods. 
Table 5. Key performance parameters (LSM during the treatment period) of the Murrah buffalo on treatment diets ${ }^{1}$

\begin{tabular}{|c|c|c|c|c|c|c|c|}
\hline Variable & \multicolumn{3}{|c|}{ High-straw diet } & $\begin{array}{c}\text { Positive } \\
\text { control (PC) }\end{array}$ & \multicolumn{3}{|c|}{ Contrast ( $P$-value $)$} \\
\hline BW change $(\mathrm{kg} / \mathrm{d})$ & -1.00 & -0.30 & -0.07 & 0.38 & $<0.01$ & 0.34 & $<0.01$ \\
\hline DMI $(\mathrm{kg} / \mathrm{d})$ & 11.0 & 10.7 & 12.4 & 16.0 & 0.11 & 0.15 & $<0.01$ \\
\hline Milk yield $(\mathrm{kg} / \mathrm{d})$ & 6.66 & 6.25 & 6.47 & 7.11 & 0.55 & 0.29 & 0.02 \\
\hline Feed gross energetic efficiency (Mcal/Mcal) & 0.02 & 0.09 & 0.13 & 0.17 & $<0.01$ & 0.74 & $<0.01$ \\
\hline Apparent $\mathrm{NE}_{\mathrm{L}}$ intake $(\mathrm{Mcal} / \mathrm{d})$ & 10.6 & 13.5 & 16.6 & 21.2 & 0.01 & 0.21 & 0.01 \\
\hline Apparent $\mathrm{NE}_{\mathrm{L}}$ density (Mcal/kg of $\left.\mathrm{DM}\right)$ & 0.98 & 1.25 & 1.37 & 1.33 & 0.02 & 0.65 & 0.35 \\
\hline
\end{tabular}

${ }^{1}$ No AFEX (ammonia fiber expansion) $=70 \%$ untreated straw; low AFEX $=45 \%$ untreated straw with 25\% AFEX-treated straw; high AFEX $=20 \%$ untreated straw with 50\% AFEX-treated straw; positive control = nutrient-rich diet with $20 \%$ straw.

${ }^{2} P$-value for linear comparison of no, low, and high AFEX treatments based on the percentage of AFEX pellets in the diets.

${ }^{3} P$-value for quadratic comparison of no, low, and high AFEX treatments based on the percentage of AFEX pellets in the diets.

${ }^{4} P$-value for the comparison between positive control treatment and average of the no, low, and high AFEX treatments.

${ }^{5}$ Average BW during the treatment period.

altered by gut fill and poorly related to body energy change. This lack of change in body energy was validated by the BCS, which showed no significant increase $(P>0.05)$ for the PC diet over the other diets during the course of the study (Figure $2 \mathrm{~d}$ ).

Figure 2 shows the time-course of milk energy, DMI, BW, and BCS of the 4 treatment groups. Cattle fed the $\mathrm{PC}$ diet greatly increased their DMI in the second week of treatment period compared with the first $(P<0.01)$. This increased DMI was concurrent with, and likely due to, the replacement of fresh chopped maize forage with fresh chopped forage sorghum, caused by declining quality of the maize forage. Although there was a linear effect of treatment on DMI, the DMI for all high-straw diets was similar during the post-treatment phase $(P$ $>0.05)$. Milk energy and BW did not substantially change between wk 3 and 4 on the treatment diet for all treatments $(P>0.05)$. Cattle fed PC increased in BW during wk $5(P<0.01)$, again likely due to the change in the source of forage, whereas animals fed the no AFEX diet lost BW in wk $4(P<0.01)$. The BW of cattle fed the high AFEX diet began to increase again in the first week of refeeding PC in the posttreatment period $(P=0.04)$, whereas animals on the

Table 6. Key performance parameters (LSM during the treatment period) of Karan-Fries cattle on treatment diets $^{1}$

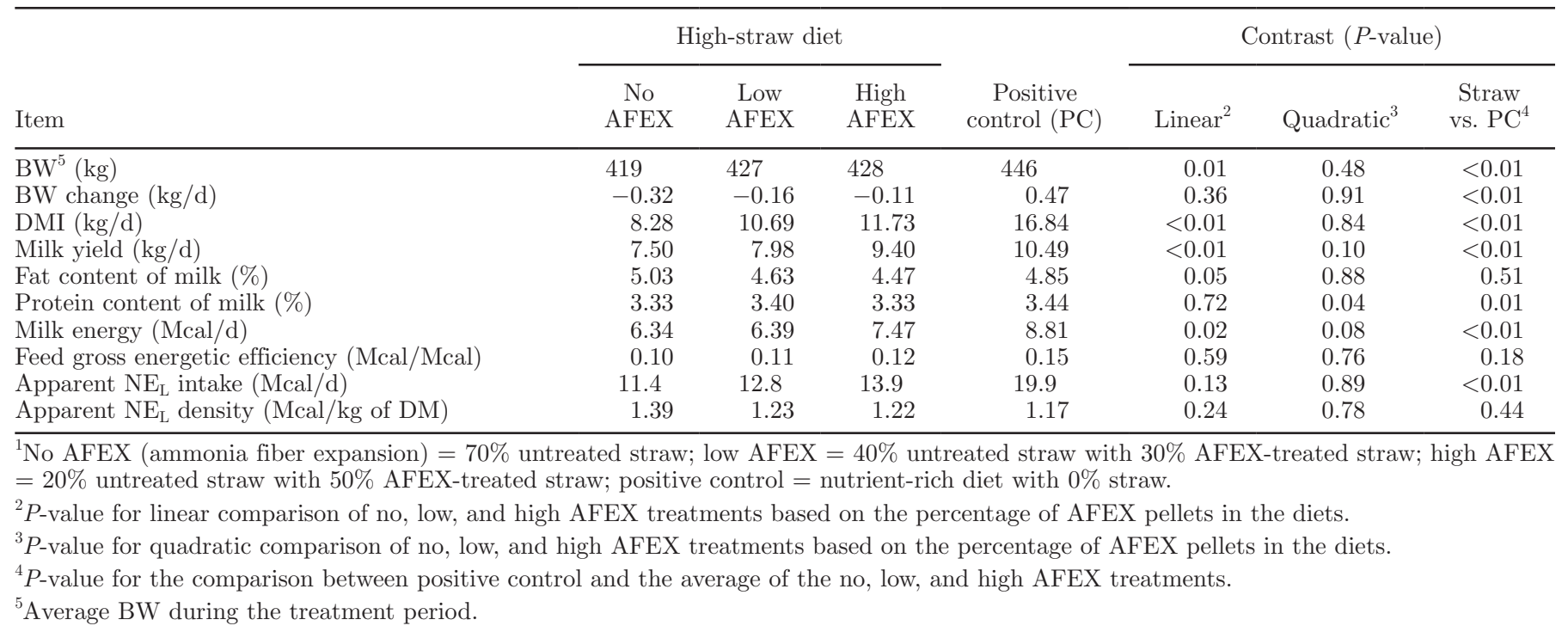


no AFEX diet gained BW in both wk 1 and 3 of the post-treatment period $(P<0.05)$.

\section{Digestibility of Diets}

Digestibility of DM, OM, CP, NDF, and ADF for each diet are shown in Table 7. As expected, the no AFEX diet was numerically the least digestible diet for all components in the feed, likely because $70 \%$ of the diet was untreated wheat straw. Treatment with AFEX linearly increased the digestibility of all components of the feed in both experiments $(P<0.01)$. There was also evidence of a quadratic effect for $\mathrm{CP}$ and $\mathrm{ADF}$ digestibility for buffalo as well as DM, OM, and CP digestibility for cattle. The digestibility of NDF was increased 10 percentage points for buffalo and 6 percentage points for cattle fed high AFEX compared with no AFEX. The buffalo results are similar to an in vitro digestibility test on the straw used in this study, which showed a 21-percentage-point improvement (increase from 43 to $64 \%$ ) in NDF digestibility at $48 \mathrm{~h}$ after AFEX treatment. With the exception of ADF digestibility in buffalo $(P=0.29)$, the $\mathrm{PC}$ diet had greater digestibility for all components than the average of the high-straw diets $(P<0.01)$. For buffalo, increasing inclusion of AFEX-treated straw linearly increased digestibilities of components in the straw diets $(P<$ 0.01 ), so that the high AFEX diet was numerically similar to the PC diet. For cattle, increasing AFEX in the high-straw diets also linearly increased digestibility of all components $(P<0.01)$.

\section{Sensory Analysis}

The sensory analysis discerned no effect of AFEXtreated straw on the taste of the milk. Only 2 of the 24 buffalo samples were reported as having an off-flavor: 1 for the animals fed no AFEX and 1 for the animals fed PC. Only 5 of the cow samples were reported as having an off-flavor: 1 each for the high AFEX, no AFEX, and PC diets, and 2 for the low AFEX diet. Each taster was provided with duplicate samples, but in all instances of an off-flavor in 1 sample, the duplicate sample did not have a detectable off-flavor. For all off-flavors detected, the testers commented that the off-flavor was very slight. Given that off-flavors were slight, distributed equally among all treatments, and not replicable, we concluded that AFEX pellets did not affect the taste of the milk.

\section{DISCUSSION}

Our results showed that AFEX treatment of wheat straw increased its digestibility and energy availability when it was fed to lactating dairy animals. Compared with urea-treated straw fed at $70 \%$ of the diet, pelletized AFEX-treated straw increased milk production in Karan-Fries cattle and enabled Murrah buffalo to maintain rather than lose BW. These effects of AFEX corresponded to the effects of feeding high straw for each species; when fed a high-straw diet compared with the PC diet, cattle lost milk production whereas buffalo lost BW.

Table 7. Digestibility (\%) of diets during wk 3 of treatment ${ }^{1}$ for Murrah buffalo (experiment 1) and Karan-Fries cattle (experiment 2)

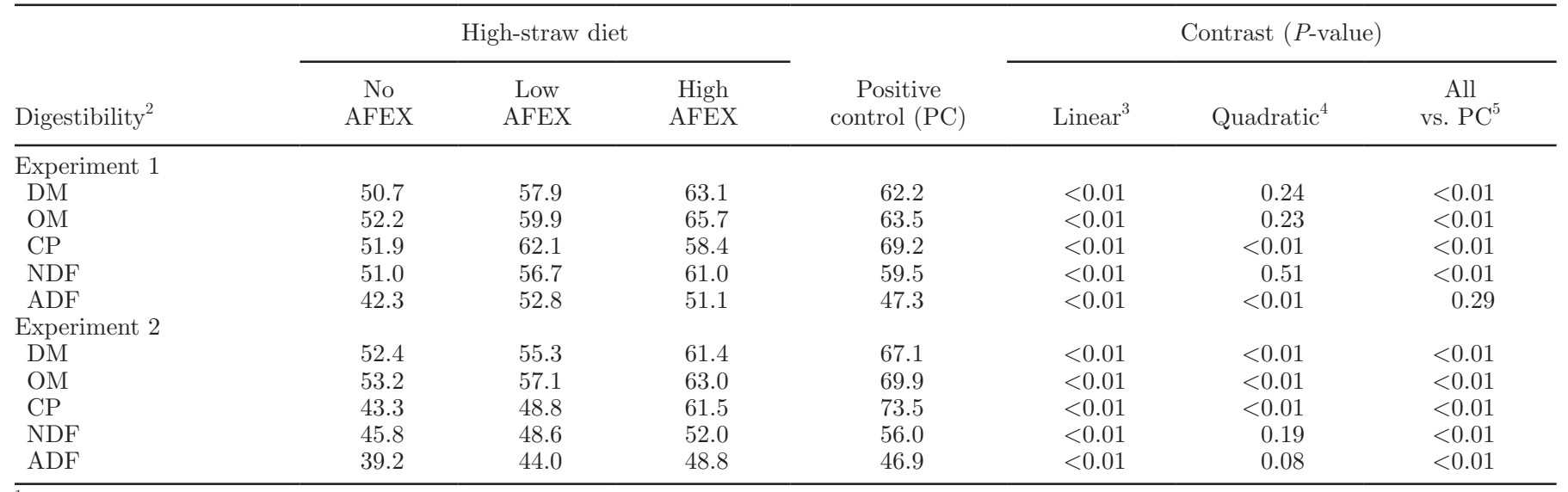

${ }^{1}$ No AFEX (ammonia fiber expansion) $=70 \%$ untreated straw; low AFEX $=40$ to $45 \%$ untreated straw with 25 to $30 \%$ AFEX-treated straw; high AFEX $=20 \%$ untreated straw with 50\% AFEX-treated straw; positive control = nutrient-rich diet with 0 to $20 \%$ straw.

${ }^{2}$ Values are least squares means of 6 animals tested during wk 3 of treatment.

${ }^{3} P$-value for linear comparison of no, low, and high AFEX treatments based on the percentage of AFEX pellets in the diets.

${ }^{4} P$-value for quadratic comparison of no, low, and high AFEX treatments based on the percentage of AFEX pellets in the diets.

${ }^{5} P$-value for the comparison between positive control and the no, low, and high AFEX treatments. 
We observed no adverse health effects in this study for either cattle or buffalo consuming AFEX pellets (at up to $50 \%$ of the diet). It is known that consumption of forages ammoniated at elevated temperatures can induce hyperexcitability in cattle (Perdok and Leng, 1987). Although the exact cause is unknown, it is believed to be linked to the presence of high reducing sugars in the forage before ammoniation. Mature cereal straws such as the wheat straw used in these experiments are low in reducing sugars, and thus it is not surprising that no hyperexcitability was observed in this trial. Previous tests with AFEX-treated corn stover in the United States also showed no adverse health effects on steers over $160 \mathrm{~d}$ (Blummel et al., 2014) or sheep (unpublished data). The effect of ammoniation of feed on human food products has not been previously described in the literature, and more detailed studies are currently underway to evaluate the suitability of milk from animals fed ammoniated forages for human consumption, and will be published at a later date.

These responses in cattle and buffalo were surprising but not unprecedented. A reduction in BW rather than milk yield in Murrah buffalo was reported by Van Thu and Uden (2000) for animals that were not given ureamolasses cake supplements in their diets. Zava and Sansinena (2017) also observed that nutritionally restricted buffalo will mobilize body reserves to maintain milk production. In addition, the buffalo in our study had greater fat reserves to mobilize for lactation than did the cattle. The initial BCS of the buffalo was $3.8 \mathrm{com}-$ pared with 3.0 for cattle, as shown in Figure 1d and 2d. Chilliard (1992) reported that leaner cows responded to lesser energy intake by producing less milk, whereas fatter cows responded to the same diets by losing BW.

The BW changes were confirmed partly by the BCS of the animals, as seen in Figure 1d and 2d. However, the changes in BW were likely also partly caused by changes in feed intake and thus gut fill. This is consistent with the fact that the BW changes were primarily within the first $2 \mathrm{wk}$ of treatment, and BW began to return to baseline after the animals returned to the PC diet.

One shortfall of our study is that the PC diet for buffalo had 4 times the amount of concentrate as the high-straw diets (no, low, and high AFEX diets). The PC diet had more concentrate so that we could assess the milk production potential of the buffalo. However, because the mineral premix was included as a component of the concentrate mix, the buffalo on the highstraw diets received less mineral than those fed the PC diet. Although the mineral supplementation of highstraw diets may have been low relative to other studies using Murrah buffalo (Singh et al., 2003; Shekhar et al., 2010), the amount of mineral supplement was similar across all 3 high-straw treatments. Although the buffalo fed high-straw diets were fed diets that would typically be considered deficient in mineral and protein content based on cattle diets in North America or Europe and based on NRC (2001), diets low in mineral and protein are often fed to buffalo by poor farmers during the dry season in northern India. For the objectives of the current study, it was important that the negative control diet (the no AFEX diet) be similar to that fed by lowincome Indian farmers.

Buffalo fed the no AFEX diet exhibited significant losses in BW and body condition, but AFEX treatment ameliorated these losses so that BW and BCS of cows fed AFEX-treated diets were similar to those of cows on the PC diet, despite the fact that these animals were not given additional mineral or protein supplements. We suggest that these responses show that the decreased mineral and protein content of the high-straw diets was not the major impediment to buffalo performance, but rather that the change in content and digestibility of fiber caused most treatment effects.

Cattle responded to the low-quality high-straw diets by reducing milk output. Many other studies on nutrient-deficient diets in the developing world focused specifically on protein deficiency, particularly on the value of urea-molasses supplements (FAO, 2007). However, our objective was to determine the effect of AFEX on energy availability of the straw due rather than on its nitrogen availability. Thus, the no AFEX diet was made to be isonitrogenous with the low and high AFEX diets via urea supplementation. The NPN in the AFEX diet is due mostly to acetamide (Chundawat et al., 2010), which is less available than urea (Belasco, 1954); thus, we expected that replacing urea-supplemented untreated straw with AFEX pellets might decrease nitrogen digestibility. However, CP digestibility increased with increasing AFEX inclusion in cattle and buffalo, as shown in Table 7.

The increases in BW and milk yield due to AFEX treatment of high-straw diets was matched by greater DM, OM, and NDF digestibility. In the buffalo trial, $\mathrm{DM}, \mathrm{OM}, \mathrm{NDF}$, and ADF digestibility were greater in the high AFEX diet than in the PC diet. Previous in vitro tests have demonstrated that AFEX-treated fodder, such as straw, can have greater NDF digestibility than untreated high-quality forages (Bals et al., 2010). In contrast, CP digestibility was much lower in both experiments in all straw diets compared with the PC diet. Given the lower protein content, lower digestibility, and lower DMI, it is possible that the high-straw diets were protein limited, which may have decreased milk yield or BW.

The AFEX-treated straw was fed in pelleted form to the animals, whereas urea-supplemented straw was 
fed as chopped straw. We recognize that pelletizing the straw might have caused some of the effects attributed to AFEX treatment. It is known, for example, that decreasing the particle size of fiber can alter digestibility and DMI (Yang et al., 2002; Teimouri Yansari et al., 2004). In a previous unpublished pilot study, we fed AFEX-treated corn stover in unpelleted $(\sim 5 \mathrm{~cm}$ particle size, similar to that of the untreated wheat straw in the present experiment) and pelleted forms to growing steers. No differences were observed in DMI (5.5 $\mathrm{kg} / \mathrm{d}$ unpelleted vs. $5.3 \mathrm{~kg} / \mathrm{d}$ pelleted), DM digestibility (63.9 vs. $63.9 \%$ ), or NDF digestibility (58.3 vs. $58.7 \%$ ). Manriquez et al. (2016) also observed no difference in $\mathrm{OM}$ or NDF digestibility for unpelleted versus pelleted wheat straw. Thus, the difference in value between the no AFEX and high AFEX diets might be due primarily to the AFEX treatment rather than pelletization, although it is not possible to separate the effects in this study.

The AFEX treatment of straw increased energy availability in cattle and buffalo, as was expected from in vitro digestibility studies (Bals et al., 2010; Scott et al., 2011; Griffith et al., 2016). Studies using different varieties of forages in the United States have shown that relatively small differences in fiber digestibility can lead to large changes in milk yield, likely because greater fiber digestibility enables greater feed intake (Oba and Allen, 1999).

\section{Post-Treatment Effects}

One noticeable aspect of this study was that returning to the $\mathrm{PC}$ diets did not necessarily return $\mathrm{BW}$ or milk yield to their previous values. Most notably, the milk yield of the no and low AFEX treatments in the cattle experiment did not return to that of $\mathrm{PC}$ cattle in the 3-wk post-treatment period. Likewise, buffalo on the no AFEX treatment did not gain BW after the treatment period ended. This is in contrast to Gross et al. (2011), who observed a return to control values for both milk yield and BW after only 3 wk following restricted feeding of Holstein cows. Although milk yields of cattle appeared to be returning to the same level as that of animals fed the PC diet, and thus may have fully recovered if the post-treatment period had continued beyond $3 \mathrm{wk}$, the BW and BCS of buffalo fed the no AFEX diet showed no evidence of a return to normal in the post-treatment period, despite the fact that their DMI had increased significantly. It is unclear why the buffaloes did not regain BW. However, others have observed similar effects when buffalo are severely undernourished. For example, Mavi et al. (2011) observed that Murrah buffalo with a high BW loss around parturition produced less milk and continued to lose
BW as lactation progressed, and had worse conception rates. Kaur and Arora (1995) reported that feed deficiency resulted in infertility in cows and buffaloes. If the Murrah buffalo were to lose weight during a seasonal period of poor-quality feeds, long-term reductions in their value could be expected for the farmer. Thus, increasing the availability of energy in straw via AFEX treatment during periods of poor feed availability could enable dramatic improvements in farmer revenue. Future studies should examine this potential benefit of AFEX treatment.

\section{Revenue}

The primary purpose of this study was to determine whether AFEX-treated straw would be a viable alternative to green forages when high-quality forages are scarce. As such, the results of this study were evaluated in economic terms, as shown in Table 8. Fixed costs and labor associated with raising animals were not included in this study. Feed costs were based on expert opinions from Indian cattle researchers and were assumed 13,5 , and 20 Indian rupees $(\mathbf{I N R} ; 100 \mathrm{INR}=\$ 1.50)$ per $\mathrm{kg}$ of DM for concentrate, wheat straw, and good forage during times of scarcity, respectively. Concentrate and green forage prices were estimated by NDRI, whereas the wheat straw price was estimated based on market conditions in Uttar Pradesh (P. George, Sam Higginbottom Institute of Agriculture, Technology, and Sciences, Allahabad, India; personal communication). The processing cost of AFEX treatment of straw was assumed to be $4 \mathrm{INR} / \mathrm{kg}$ based on Michigan Biotechnology Initiative internal assessment and included costs of transportation but not the cost of the feedstock itself. The high cost of green forage was based on its value in the dry season when it is not readily available. The milk revenue price was based on $600 \mathrm{INR} / \mathrm{kg}$ of milk fat and was provided by the Gujarat Co-Operative Milk Marketing Federation Ltd. (Anand, India).

The milk income over feed cost for the buffalo was very similar for the 3 high-straw diets, between 193 and $205 \mathrm{INR} / \mathrm{d}$. Although this was substantially higher than that of the PC diet, AFEX treatment provides no financial return based solely on milk income and feed costs. For cattle, milk income over feed costs was slightly lower in the AFEX treatments compared with the no AFEX treatment. However, the differences in BW, which did not fully recover in the post-treatment period, may lead to long-term reductions in cash flow and should be considered. For this study, we assumed the BW change to have a value of $81 \mathrm{INR} / \mathrm{kg}$, based upon the selling price of buffalo meat (carabeef). We also included the post-treatment period by comparing the income over feed costs during the post-treatment 
Table 8. Estimated costs and revenue from each treatment ${ }^{1}$ for both experiments

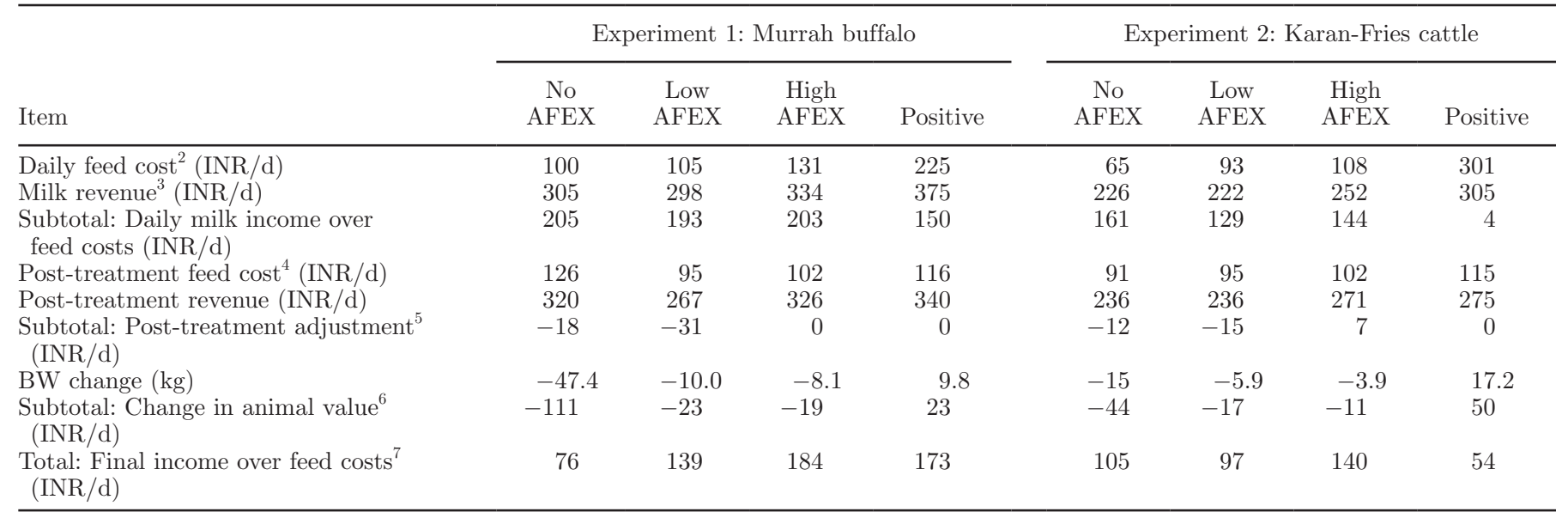

${ }^{1}$ No AFEX (ammonia fiber expansion) $=70 \%$ untreated straw; low AFEX $=40$ to $45 \%$ untreated straw with 25 to $30 \%$ AFEX-treated straw; high AFEX $=20 \%$ untreated straw with $50 \%$ AFEX-treated straw; positive $=$ positive control nutrient-rich diet with 0 to $20 \%$ straw.

${ }^{2}$ Feed costs were assumed to be 13, 5, 9, and 20 Indian rupees (INR) per kg (DM) of concentrate, wheat straw, AFEX pellets, and forage, respectively $(100 \mathrm{INR}=\$ 1.50)$. Data for intake are shown as least squares means during the course of treatment.

${ }^{3}$ Milk revenue was assumed to be $600 \mathrm{INR} / \mathrm{kg}$ of milk fat. Data for milk fat are shown as least squares means during the course of the treatment.

${ }^{4}$ Post-treatment feed cost is identical to regular feed cost except forage price dropped to $4 \mathrm{INR} / \mathrm{kg}$ of DM.

${ }^{5}$ Value shown is the differences in post-treatment milk income over feed cost between treatments and the positive control. This difference is over $3 \mathrm{wk}$, and thus the value is amortized over the treatment period (5 wk for experiment 1, $4 \mathrm{wk}$ for experiment 2).

${ }^{6}$ Change in value due to BW was assumed to be $81 \mathrm{INR} / \mathrm{kg}$, amortized over the treatment period.

${ }^{7}$ Sum of "daily milk income over feed costs," "post-treatment adjustment," and "change in animal value" rows.

period to the PC diet (the diet used in the post-treatment period). The total difference in income over feed costs relative to the PC diet (summed over the 3 -wk post-treatment period) was then amortized over the treatment period ( $5 \mathrm{wk}$ for buffalo and $4 \mathrm{wk}$ for cattle). For the post-treatment period, we assumed that the forage is seasonally available or no longer scarce, and thus assumed a much lower price for the good forage (4 INR/kg of DM). Note that this adjustment assumed that the scarcity of forage would only last for 4 to $5 \mathrm{wk}$, which is unrealistic but unavoidable given the limitations of the current study.

By including the change in BW and the post-treatment adjustment period into the overall value, the high AFEX treatment was the most valuable treatment in both experiments. In the buffalo experiment, the total value was $108 \mathrm{INR} / \mathrm{d}$ per animal higher than the no AFEX group, primarily due to the reduction in $\mathrm{BW}$ in the no-AFEX diet. Although the economic value of this change in $\mathrm{BW}$ is speculative, it is indicative of the importance in determining the long-term effect of BW loss in the buffalo. The high AFEX and PC diets had similar profit, also due to differences in BW loss. Although the BCS did indicate a decrease in body condition for the no AFEX treatment, no differences were observed between the PC and high AFEX treatments. For the cattle experiment, both the change in $\mathrm{BW}$ and the post-treatment adjustment were important in in- creasing the value of the high AFEX treatment over the no AFEX treatment, increasing profit over the latter diet by $35 \mathrm{INR} / \mathrm{d}$ per animal ( $\$ 0.50 / \mathrm{d}$ per animal).

According to the Rangarajan panel in 2011, the poverty line for rural India is $32 \mathrm{INR} / \mathrm{d}$ per person (Government of India, 2014). Thus, in times of drought, a family of 5 with 2 buffalo (a typical arrangement) would be slightly below the poverty line if feeding a highstraw diet (no AFEX). In contrast, including AFEX in the diet could maintain a standard of living at $\sim 2.3$ times the poverty level. The differences for cattle are less but could also greatly improve the standard of living. These results are highly speculative given the short time period of the trial, and more studies are needed that focus on the economic value of AFEX pellets for low-income farmers in India to fully understand their potential.

\section{Other Crop Residues}

This study was performed with wheat straw due in part to the relative simplicity of treating straw in Michigan and transporting it to India for the experiments. India has large quantities of underutilized rice straw, as well as corn stover and the straw of millet and other grains. Rice straw, in particular, is widely burned on the field in northern India, creating severe health and safety hazards in areas around Delhi (Sharma et 
al., 2010; Yadav et al., 2014). Thus, treating and selling the straw would have not only economic and food security benefits, but also health and air quality benefits. In contrast, wheat straw is already widely used as bedding and fodder in India, and thus may not be as suitable as a feedstock for AFEX treatment. Bals et al. (2010) reported a greater improvement in wheat straw digestibility compared with rice straw digestibility in vitro. However, these results were performed using a laboratory AFEX reactor with different processing conditions. Using the same pilot-scale reactor as was used for this experiment, rice straw was found to have greater improvements in digestibility in vitro compared with wheat straw (J. Macdonald, University of Nebraska, Lincoln; personal communication). Further research is required to determine the effectiveness of rice straw treatment with AFEX for dairy animals in India. The high silica content in rice straw may negatively affect fiber digestibility as well as cattle health (Van Soest, 2006). Care must also be taken to ensure that hyperexcitability or other negative health impacts from ammoniation are not incurred with rice straw or other feedstocks used in India (Perdok and Leng, 1987).

\section{CONCLUSIONS}

Ammonia fiber expansion treatment of wheat straw increased its available energy for lactating dairy animals in India. Karan-Fries cattle fed AFEX-treated straw responded by increasing milk production relative to those fed native straw, whereas Murrah buffalo responded by maintaining, rather than losing, BW.

\section{ACKNOWLEDGMENTS}

Funding for this project was provided by the Bill and Melinda Gates Foundation (OPP1142801). The work was additionally supported by Grant Case- 48166 of the 21st Century Jobs Trust Fund received through the Michigan Strategic Fund from the State of Michigan. The authors thank Jim Liesman and Rodrigo Souza (Michigan State University, Lansing) for their assistance with the statistical analysis as well as other insights. We also thank Prasanta Choudhury for analyzing milk composition, and Harikesh Yadav, Fanny Joshan, Kewal, and the rest of the NDRI staff in Karnal, India, for their assistance in the experiments.

\section{REFERENCES}

AFRC (Agricultural and Food Research Council). 1993. Energy and Protein Requirements of Ruminants. CAB International, Wallingford, UK.

Bals, B., H. Murnen, M. Allen, and B. Dale. 2010. Ammonia fiber expansion (AFEX) treatment of eleven different forages: Improve- ments to fiber digestibility in vitro. Anim. Feed Sci. Technol. 155:147-155.

Belasco, I. J. 1954. New nitrogen feed compounds for ruminants-A laboratory evaluation. J. Anim. Sci. 13:601-610.

Blummel, M., B. Steele, and B. E. Dale. 2014. Opportunities from second-generation biofuel technologies for upgrading lignocellulosic biomass for livestock feed. Perspect. Agric. Vet. Sci. Nutr. Nat. Resour. 9:1-8.

Chilliard, Y. 1992. Physiological constraints to milk production: Factors which determine nutrient partitioning, lactation persistency and mobilization of body reserves. World Rev. Anim. Prod. 27:1926.

Chundawat, S. P. S., R. Vismeh, L. N. Sharma, J. F. Humpula, L. C. Sousa, C. K. Chambliss, A. D. Jones, V. Balan, and B. E. Dale. 2010. Multifaceted characterization of cell wall decomposition products formed during ammonia fiber expansion (AFEX) and dilute acid pretreatments. Bioresour. Technol. 101:8429-8438.

Deshmukh, S. S., and K. P. Jadhav. 2015. Status, growth, problem, and prospects of milk industry in India. Trends Biosci. 8:929-936.

Eranki, P. L., B. D. Bals, and B. E. Dale. 2011. Advanced regional biomass processing depots: A key to the logistical challenges of the cellulosic biofuel industry. Biofuels Bioprod. Biorefin. 6:621-630.

FAO. 2007. Feed supplementation blocks. Animal Production and Health, Food and Agricultural Organization, Rome, Italy.

Goering, H. K., and P. J. Van Soest. 1970. Forage fiber analyses (apparatus, reagents, procedures, and some applications). Agric. Handbook 379. USDA Agricultural Research Service, Washington, DC

Government of India. 2011. Report of the working group on animal husbandry and dairying: 12th five-year plan (2012-2017). F. No. Q.12043/1/2010-Agric. Planning Commission, Government of India, New Delhi, India.

Government of India. 2014. Rangarajan Report on Poverty. Press Information Bureau, 07-Aug 2014. Government of India, New Delhi, India.

Griffith, C. L., G. O. Ribeiro, M. Oba, T. A. McAllister, and K. A. Beauchemin. 2016. Fermentation of ammonia fiber expansion treated and untreated barley straw in a rumen simulation technique using rumen inoculum from cattle with slow versus fast rate of fiber disappearance. Front. Microbiol. 7:1839.

Gross, J., H. A. van Dorland, R. M. Bruckmaier, and F. J. Schwarz. 2011. Performance and metabolic profile of dairy cows during a lactational and deliberately induced negative energy balance with subsequent realimentation. J. Dairy Sci. 94:1820-1830.

Kaur, H., and S. P. Arora. 1995. Dietary effects on ruminant livestock reproduction with particular reference to protein. Nutr. Res. Rev. $8: 121-136$

Manríquez, O. M., M. F. Montano, J. F. Calderon, J. A. Valdez, J. O. Chirino, V. M. Gonzalez, J. Salinas-Chavira, G. D. Mendoza, S. Soto, and R. A. Zinn. 2016. Influence of wheat straw pelletizing and inclusion rate in dry rolled or steam-flaked corn-based finishing diets on characteristics of digestion for feedlot cattle. Asianaustralas. J. Anim. Sci. 29:823-829.

Mavi, P. S., C. S. Bahga, H. K. Verman, S. K. Uppal, and S. S. Sidhu. 2011. Postpartum performance as influenced by body weight changes at parturition in buffaloes. Indian J. Anim. Reprod. $32: 61-63$.

Mishra, S., S. Sharma, P. Vasudevan, R. K. Bhatt, S. Pandey, M. Singh, B. S. Meena, and S. N. Pandey. 2010. Livestock feeding and traditional healthcare practices in Bundelkhand region of Central India. Indian J. Tradit. Knowl. 9:333-337.

NRC. 2001. Nutritional Requirements for Dairy Cattle. 7th rev. ed. The National Academies Press, Washington, DC.

Oba, M., and M. S. Allen. 1999. Evaluation of the importance of the digestibility of neutral detergent fiber from forage: Effects on dry matter intake and milk yield of dairy cows. J. Dairy Sci. 82:589596.

Perdok, H. B., and R. A. Leng. 1987. Hyperexcitability in cattle fed ammoniated roughages. Anim. Feed Sci. Technol. 17:121-143.

Sarks, C., B. D. Bals, J. Wynn, F. Teymouri, S. Schwegmann, K. Sanders, M. Jin, V. Balan, and B. E. Dale. 2016. Scaling up and benchmarking of ethanol production from pelletized pilot scale 
AFEX treated corn stover using Zymomonas mobilis 8b. Biofuels $7: 253-262$.

Sarnklong, C., J. W. Cone, W. Pellikaan, and W. H. Hendriks. 2010. Utilization of rice straw and different treatments to improve its feed value for ruminants: A review. Asian-australas. J. Anim. Sci. 23:680-692.

Schiere, J. B., and J. de Wit. 1995. Feeding of urea straw in the tropics. II. Assumptions on nutritive value and their validity for least cost ration formulation. Anim. Feed Sci. Technol. 51:45-63.

Scott, S. L., R. S. Mbifo, J. Chiquette, P. Savoie, and G. Turcotte. 2011. Rumen disappearance kinetics and chemical characterization of by-products from cellulosic ethanol production. Anim. Feed Sci. Technol. 165:151-160.

Sharma, A. R., S. K. Kharol, K. V. S. Badarinath, and D. Singh. 2010. Impact of agriculture crop residue burning on atmospheric aerosol loading - A study over Punjab State, India. Ann. Geophys. 28:367-379.

Shekhar, C. S. S. Thakur, and S. K. Shelke. 2010. Effect of exogenous fibrolytic enzymes supplementation on milk production and nutrient utilization in Murrah buffaloes. Trop. Anim. Health Prod. 42:1465-1470

Singh, M., D. P. Tiwari, A. Kumar, and M. R. Kumar. 2003. Effect of feeding transgenic cottonseed vis-à-vis non-transgenic cottonseed on haematobiochemical constituents in lactating Murrah buffaloes. Asian-australas. J. Anim. Sci. 16:1732-1737.

Teimouri Yansari, A., R. Valizadeh, A. Naserian, D. A. Christensen, P. Yu, and F. E. Shahroodi. 2004. Effects of alfalfa particle size and specific gravity on chewing activity, digestibility, and performance of Holstein dairy cows. J. Dairy Sci. 87:3912-3924.

Van Soest, P. J. 2006. Rice straw, the role of silica and treatments to improve quality. Anim. Feed Sci. Technol. 130:137-171.

Van Soest, P. J., J. B. Robertson, and B. A. Lewis. 1991. Methods for dietary fiber, neutral detergent fiber, and nonstarch polysaccharides in relation to animal nutrition. J. Dairy Sci. 74:3583-3597.

Van Thu, N., and P. Uden. 2000. Effect of work and urea-molasses cake supplementation on live weight and milk yield of Murrah buffalo cows. Asian-australas. J. Anim. Sci. 13:1329-1336.

Weimer, P. J., D. R. Mertens, E. Ponnampalam, B. F. Severin, and B. E. Dale. 2003. FIBEX-treated rice straw as a feed ingredient for lactating dairy cows. Anim. Feed Sci. Technol. 103:41-50.

Yadav, M., M. P. Sharma, R. Prawasi, R. Khichi, P. Kumar, V. P. Manda, A. Salim, and R. S. Hooda. 2014. Estimation of wheat/rice residue burning in major districts of Haryana. India, using remote sensing data. Photonirvachak (Dehra Dun) 42:343-352.

Yang, W. Z., K. A. Beauchemin, and L. M. Rode. 2002. Effects of particle size of alfalfa-based dairy cow diets on site and extent of digestion. J. Dairy Sci. 85:1958-1968.

Zava, M. A., and M. Sansinena. 2017. Buffalo dairy production: A review. Pages 225-261 in The Buffalo (Bubalus bubalis) Production and Research. G. A. Presicce, ed. Bentham E-Books, Sharjah, United Arab Emirates. 